\title{
$\mathscr{B} N N \exists H-\forall \forall N \quad$ Article de synthèse
}

\section{Peptides du lait à activité biologique}

\author{
J.L. Maubois et J. Léonil \\ Laboratoire de recherches de technologie laitière, INRA, 65, rue de Saint-Brieuc, 35042 Rennes \\ Cedex, France
}

(reçu le 21 février 1989, accepté le 4 avril 1989)

Résumé - Plus que tout autre composant du lait, les protéines caractérisent très finement le patrimoine génétique des mammifères. Pendant longtemps, il a été postulé que leur apport dans la nutrition du jeune ou de l'adulte se limitait à la fourniture de l'azote requis par la biosynthèse des protides tissulaires ou circulants et par celle des acides nucléiques. Les connaissances acquises au cours de la dernière décennie, en matière de physiologie et de biochimie de la nutrition azotée, ont montré que de nombreux segments peptidiques résultant de l'action des protéases du tractus digestif n'avaient pas seulement un rôle d'apport d'acides aminés aux organismes, mais intervenaient dans la physiologie soit directement comme neurotransmetteurs, soit indirectement en déclenchant à partir des récepteurs intestinaux des sécrétions hormonales ou enzymatiques.

Tenter de faire la revue des connaissances acquises sur les rôles physiologiques identifiés des peptides présents dans la séquence des différentes protéines laitières constitue l'objectif de la première partie de la présente communication. Seront successivement présentées les activités de biotransfert d'oligo-éléments, d'opioïdes, d'immunomodulation, d'antihypertension, d'antithrombose et autres reconnues dans les enchaînements peptidiques des caséines et des protéines sériques. Le seconde partie sera consacrée aux interrogations, aux réflexions qui doivent se mettre en place au sein de l'industrie laitière pour aborder cette nouvelle valorisation de la matière première qu'elle reçoit. Peut-elle ou non aborder seule ce nouveau marché, source de haute valeur ajoutée ? Comptetenu de sa connaissance des composants du lait et de sa technicité actuelle et future en matière de technologies de séparation, de fractionnement et de fragmentation, jusqu'où peut-elle aller dans l'élaboration de produits à usage diététique, voire thérapeutique ? Quels sont les schémas, les démarches technologiques envisageables?

II est clair que les réponses pouvant être apportées sont loin d'être évidentes, compte tenu des nombreuses lacunes dans nos connaissances existant à ce jour, mais les perspectives ouvertes sont telles que ce formidable challenge mérite d'être relevé.

protéine - activité thérapeutique - rôle diététique - séparation — purification — peptide

Summary - Dietetic and parapharmaceutic uses of milk protein. More than any other component of milk, the proteins determine the fine genetic character of the mammalian species. It has been long hypothesized that the protein nutrition in children and adults is limited by the availability of the nitrogen required for the biosynthesis of tissue and circulatory proteins and for the biosynthe-

\footnotetext{
* Ce texte est issu d'une conférence prononcée le 18 novembre 1988 à Québec (Canada) dans le cadre du «Colloque international sur les ingrédients laitiers».
} 
sis of nucleic acids. The current understanding on the physiology and biochemistry of nutritional nitrogen, which has developed in the last decade, has shown that the peptide fragments resulting from the action of the digestive tract proteases function not only as suppliers of amino acids to the organism but also as physiological regulators either directly in the form of neurotransmitters or indirectly by playing a role in the secretion of hormones and enzymes from the intestinal receptors.

The first part of the present communication consists of the review of literature on the physiological roles associated with peptides whose sequences are identified in milk proteins. Accordingly, the peptide sequences in either casein or serum proteins, associated with various biological functions like bioconversion of oligo-elements, opioids, immunomodulation, antihypertension, antithrombosis, etc. will be discussed.

The second part will be devoted to the questions and reflections which the dairy industry should consider before embarking on this novel utilization of the by-products. Can it or can it not tackle this new market, which is a spring of extraordinary value ? Based on the current knowledge on the milk components and the technology past and future of their separation and fractionation, to what extent can the industry go in producing these products for dietetic and therapeutic usages ? What should be the strategies and the technological approaches?

Clearly these answers are still a long way off, considering the existing of lack of knowledge. However, the potential is so great that the challenge becomes even more tempting.

protein - therapeutical activity - nutritional role - separation - purification - peptide

\section{INTRODUCTION}

Plus que tout autre composant du lait, les protéines caractérisent très finement le patrimoine génétique des mammifères. A chaque espèce correspond une proportion précise des différents composants protéiques; à chaque race correspond un polymorphisme génétique (répartition des variants) orienté par des siècles de sélection naturelle ou dirigée par les éleveurs. Tout autant que par son sang, un animal laitier peut être caractérisé par la composition fine du lait qu'il produit.

Un tel particularisme, une telle différenciation sous-entendent une étroite adaptation de la composition protéique du lait aux besoins du jeune, pour qui le lait représente, pendant la période la plus critique de son existence, l'aliment exclusif. lls remettent évidemment en cause le concept (admis pendant des décennies) selon lequel la fonction essentielle des protéines laitières se limiterait à la fourniture de l'azote requis pour la biosynthèse des protides tissulaires et circulants et à celle des acides nucléiques. Ils amènent également à revoir et à élargir le concept actuel d'une parfaite adaptation de la composition en acides aminés indispensables aux besoins nutritionnels et métaboliques du jeune mammifère (Hambraeus, 1985).

Les connaissances acquises au cours de la dernière décennie, en matière de physiologie et de biochimie de la nutrition azotée, permettent maintenant de penser que l'ingestion de protéines laitières va bien au-delà de cet apport de nutriments essentiels, aussi adapté soit-il. II s'avère, en effet, que ces composants contiennent dans leur structure des segments peptidiques ayant une activité biologique à même de déclencher, au niveau des récepteurs membranaires intestinaux, des réactions de régulation anticipative (Mendy, 1984). Ce rôle physiologique des protéines laitières se précise de plus en plus et certains n'ont pas hésité à qualifier la principale d'entre elles : la caséine $B$ de prohormone (Migliore-Samour \& Jollès, 1988).

Tenter de faire la revue des connaissances acquises sur les rôles physiolo- 
giques identifiés des peptides présents dans la séquence des différentes caséines et protéines lactosériques constitue un des objectifs de la présente communication. Seront successivement abordées les activités de biotransfert d'oligo-éléments découlant des enchaînements phosphosériques, particulièrement originaux puisqu'on ne les retrouve que dans la séquence des caséines du lait et dans celle de la phosphovitine du jaune d'œuf, d'opioïdes qui ont été attribuées à des peptides présents aussi bien dans la séquence de caséines que dans celle de protéines sériques, d'immunomodulation, d'antihypertension et d'antithrombose démontrées pour des peptides issus de l'hydrolyse enzymatique des caséines. Nous rappellerons également les propriétés physiologiques de la lactoferrine et de peptides présents en l'état dans la sécrétion lactée.

Indiquer quelles sont les possibles stratégies technologiques à mettre en place pour préparer, à partir du lait collecté par les entreprises, des produits enrichis en ces différents peptides constitue le second objectif auquel nous nous sommes attachés. Plus que tout autre secteur de l'agro-alimentaire, l'industrie laitière maîtrise à l'heure actuelle nombre de techniques séparatives dites douces, parfaitement adaptées à la sensibilité biologique des composants protéiques de la matière première (Maubois, 1984). Ses acteurs les plus avancés ont mis en place des ateliers de production en masse de protéines purifiées ou/et de peptides. Extraire de nouvelles molécules à visées thérapeutiques ou diététiques, tout en maintenant des activités conventionnelles à même de réaliser une valorisation globale des composants du lait, semble réalisable et à la portée des technicités déjà atteintes.

\section{LES PEPTIDES À ACTIVITÉS BIOLO- GIQUES IDENTIFIÉS DANS LE LAIT}

\section{Peptides intervenant dans la nutrition minérale}

Le lait $\in i$ ses dérivés sont considérés comme la source principale d'apport du calcium à l'organisme humain dans les pays développés. Ce concept recouvre, en fait, deux notions, celle d'un apport quantitatif (1 $200 \mathrm{mg}$ de $\mathrm{Ca}$ par litre de lait) et celle d'une assimilabilité élevée : $85 \%$ du calcium contenu dans la poudre de lait sort absorbés contre 22 à $72 \%$ du calcium présent dans les végétaux de la ration (Renner, 1983). L'efficacité de l'absorption intestinale du calcium du lait a été longtemps attribuée au seul lactose. Ce sucre augmenterait la perméabilité des cellules épithéliales de l'intestin aux sels de calcium (Wasserman, 1964). Sa dégradation et la transformation des composés résultants par les enzymes de la paroi aboutiraient à la formation de sels complexes solubles de calcium qui seraient absorbés principalement au niveau du dernier segment de l'intestin grêle : l'iléon (Armbrecht \& Wasserman, 1976; Renner, 1983). L'absence de $\beta$ galactosidase ou la perte de capacité d'induction de cette enzyme, bloquant la première étape de cette biotransformation, expliquerait les relations mises en évidence entre l'intolérance au lactose et l'ostéoporose (plus de $83 \%$ des personnes intolérantes sont atteintes d'ostéoporose selon Kocian, 1986). Le mécanisme intime de l'absorption du calcium du lait relié au lactose n'est pas encore complètement élucidé, pas plus que la nature exacte des sels formés dans la lumière intestinale. II est possible qu'il s'agisse d'oses-phosphates, hypothèse formulée par Dupuis et al. (1978), selon laquelle il y aurait addition d'un groupement phospha- 
te au lactose ou à ses dérivés grâce à l'activité transphosphorylase de la phosphatase alcaline, le ou les oses-phosphates étant plus solubles que les phosphates correspondants. Les résultats récemment acquis tendent à montrer que, au contraire, une partie non négligeable de l'absorption intestinale du calcium du lait se ferait selon un autre mécanisme dans lequel interviendraient des segments peptidiques originaux des caséines : les phosphopeptides.

Les caséines $\alpha_{s}$, $\beta$ et $K$ contiennent, en effet, des enchaînements de sérines phosphorylées (Fig. 1), qui confèrent à ces protéines un pouvoir chélatant très marqué vis-à-vis des alcalino-terreux $\left(\mathrm{Ca}^{++}\right.$et $\left.\mathrm{Mg}^{++}\right)$et des oligo-éléments. Cette aptitude est d'autant plus marquée que le taux de phosphorylation est élevé, c'est dire que le pouvoir séquestrant des différentes caséines se situe comme suite : $\alpha_{\mathrm{s} 2}>\alpha_{\mathrm{s} 1}>\beta>\mathrm{K}$. La répartition des phosphosérines n'est pas uniforme, ainsi, pour les caséines $\alpha_{\mathrm{s}}$ et $\beta$, la majeure partie de ces séquences phosphorylées se situe respectivement entre les résidus 61 et 80 et entre les résidus 1 à 20 (Brulé \& Lenoir, 1987). Le pouvoir chélatant élevé de ces caséino-phosphopeptides (CPP) fait que la totalité du phosphore et du calcium micellaires leur est associée. II en résulte que ces enchaînements jouent un rôle essentiel dans la stabilité des micelles de caséine et dans les mécanismes gouvernant la formation du gel lors de la coagulation du lait. Mais les caractéristiques physico-chimiques très particulières de ces CPP ont également amené à penser qu'ils intervenaient dans l'absorption intestinale des minéraux et des oligo-éléments.

Ces CPP sont, en effet, retrouvés dans la lumière intestinale chez les rats ayant reçu un régime riche en caséine (Naito et al., 1972; Naito \& Suzuki, 1974), sous une forme identique à celle obtenue lors de la digestion enzymatique in vitro de cette même caséine. La non-dégradation gastrique des séquences phosphorylées des caséines a été également illustrée par Meisel et Frister (1988), qui ont mis en évidence la présence d'un phosphopeptide issu de la caséine $\alpha_{s 1}$ de séquence

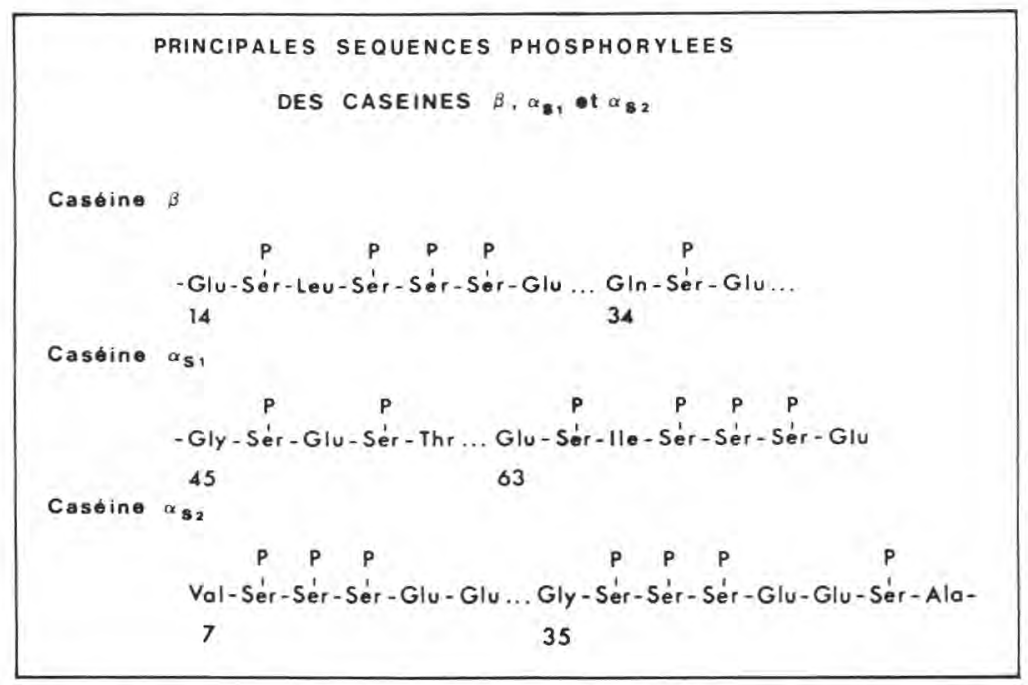

Fig. 1. Séquences des sites phosphoryles des caséines $B, \alpha_{\mathrm{s} 1}, \alpha_{\mathrm{s} 2}$. 
SerP-SerP-SerP-Glu-Glu-Ile-Val-Pro-Asn, dans le digestat recueilli chez un miniporc fistulé au niveau jéjunal après ingestion d'un aliment contenant $15 \%$ de caséine. Lors d'expériences menées sur des anses intestinales ligaturées de rats, Lee et al. (1979 a et b) ont constaté en utilisant du $\mathrm{CaCl}_{2}$ radiomarqué non seulement un accroissement de la solubilité intraluminale du calcium, mais aussi une élévation de l'absorption intestinale de cet élément. Ces derniers résultats ont été confirmés par Mykkanen \& Wasserman (1980), qui ont de plus mis en évidence que cette absorption ne nécessitait pas l'intervention de la vitamine D. Bien qu'obtenus chez le poulet, ces résultats précisaient les observations faites auparavant par Mellander (1950) sur 2 groupes d'enfants rachitiques ou non, recevant des hydrolysats trypsiques de caséine. Plus récemment, cette augmentation de la disponibilité du calcium par les CPP a été particulièrement illustrée par Gerber et Jost (1986). La mise en contact de ces segments de caséine avec des extraits embryonnaires d'os (fémur, tibia et métatarse) induisait la minéralisation de ces organes. Cette propriété était perdue si on procédait à une déphosphorylation enzymatique des CPP. Le mécanisme biochimique dans lequel interviendraient les CPP lors de l'absorption intestinale du calcium n'est pas encore totalement élucidé. Selon Sato et al. (1986), I'hypothèse la plus probable est que les CPP inhiberaient la précipitation des sels de calcium au niveau de l'intestin grêle et favoriseraient ainsi une absorption de type passif au niveau de l'iléon. Mais le décalage de plusieurs heures entre les relargages stomacaux du calcium et des CPP, mis en évidence par Péllissier et al. (1983) et Yvon et Pélissier (1987) chez le veau préruminant, soulève plusieurs questions montrant la complexité de ce mécanisme : $y$-a-t-il resolubilisation intestinale par les
CPP des sels de calcium précipités ? sous quelle forme saline se trouvent ces sels de calcium ? le calcium resolubilisé est-il celui contenu dans l'aliment ingéré ou celui relargué lors de l'ingestion du repas suivant? les CPP sont-ils protégés ou non contre l'activité des déphosphorylases intestinales?

L'isolement des phosphopeptides peut se faire soit à partir du lait ou des caséinates (Brulé et al., 1980; Gerber et Jost, 1986), soit à partir d'une des caséines, le plus souvent la caséine $\beta$ (Peterson et al., 1958; Sato et al., 1986). Après hydrolyse trypsique, les séquences phosphopeptidiques sont agrégées soit par mise en contact avec du calcium et du phosphate minéral, soit par addition de chlorure de baryum (Peterson et al., 1958). La séparation et la purification de l'agrégat se fait pas ultrafiltration sur membrane (Fig. 2) ou par gel filtration ou encore par chroma-

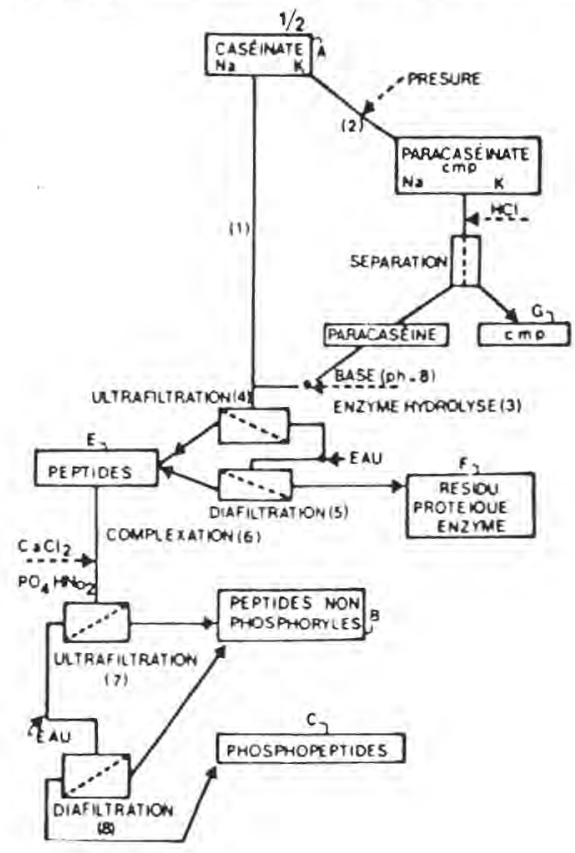

Fig. 2. Schéma de préparation de phosphopeptides à partir de caséinate (Brulé et al., 1980). 
tographie d'échange d'ions. Les préparations commerciales se caractérisent par une teneur élevée en acide glutamique (28 pour cent $\mathrm{g}$ ), en sérine ( 9 pour cent g), en calcium ( 7 pour cent $g$ ) et en phosphore $(3,6$ pour cent $\mathrm{g}$ ) (Touraine et al., 1987 ) et une très grande solubilité (200 g/l). Elles peuvent chélater des oligo-éléments en quantité élevée, sans que soit altérée leur solubilité. Brulé et al. (1980) ont ainsi pu fixer sur $100 \mathrm{~g}$ de phosphopeptides $6 \mathrm{~g}$ de calcium, $10 \mathrm{~g}$ de cuivre, 5 $\mathrm{g}$ de zinc, $12 \mathrm{~g}$ de fer $\mathrm{Fe}^{++}$ou $5 \mathrm{~g}$ de fer $\mathrm{Fe}^{+++}$. Ces mêmes auteurs (Brulé et al., 1982, travaux non publiés) ont également montré que les CPP avaient la propriété de catalyser rapidement l'oxydation du $\mathrm{Fe}^{++}$en $\mathrm{Fe}^{+++}$en présence d'oxygène, propriété déjà démontrée pour plusieurs autres composés phosphorylés (KoryckaDahl \& Richardson, 1980).

\section{Peptides à activité opiacée}

Le relargage de peptides à activité opiacée lors de l'hydrolyse digestive de protéines alimentaires a été mis en évidence lors de recherches portant sur les liens de causalité existant entre la psychose schizophrénique et le régime alimentaire (Paroli, 1988). En effet, de nombreuses observations réalisées chez les personnes prédisposées à la schizophrénie avaient montré une étroite corrélation entre la consommation de céréales, voire de lait, et le syndrôme de la maladie cœliaque (entéropathie). Ces symptômes étaient supprimés lorsque la gliadine (une des protéines du gluten) était éliminée du régime. L'administration de gluten, de soja ou de lait les faisait, au contraire, réapparaître. Ces observations, jointes à celles relatives aux modifications de comportement d'animaux ayant reçu, par voie orale ou par injection intracérébrale, des hydrolysats enzymatiques de gluten, ont amené les chercheurs à supposer un effet psychotoxique direct d'un peptide de la gliadine.

La similarité des symptômes observés et de ceux reliés à la sécrétion de peptides à activité opiacée par le cerveau et la glande pituitaire (les enképhalines et les endorphines) a conduit à qualifier les peptides d'origine alimentaires d'exorphines (Klee et al., 1978). Ces exorphines ont été mises en évidence dans les hydrolysats pepsiques de gluten de blé, de caséine $\alpha_{\mathrm{s}}$ (Zioudrou et al., 1979) et de caséine $\beta$ (Brantl et al., 1979). Le fait que la totalité de leurs séquences primaires ait été élucidée a permis une avancée très rapide des recherches portant sur les activités exorphiques présentes dans les protéines laitières. Ainsi, Henschen et al. (1979) ont-ils pu rapidement attribuer à l'enchaînement $60-66$ de la caséine $\beta$ bovine : Tyr-Pro-Phe-Pro-Gly-Pro-lle et à ses dérivés l'activité morphinomimétique détectée dans une caséine-peptone commerciale. Cette séquence a été dénommée $\beta$-casomorphine 7 . La nécessaire présence des enchaînements Tyr-X-Phe ou Tyr- $X_{1}-X_{2}-$ Phe dans les peptides à activité opiacée d'origine endogène ou exogène a permis de montrer l'existence de nombreuses exorphines dans la séquence des protéines du lait produit par les différentes espèces de mammifères (Chiba et Yoshikawa, 1986) (Fig. 3). Si les caséines $\alpha_{\mathrm{s}}$ et $\beta$ apparaissent comme les principales sources de ce type de peptides, que ce soit dans le lait humain ou dans le lait bovin : des séquences proches voire identiques ont également été retrouvées dans les caséines de brebis (Richardson \& Mercier 1979), de bufflesse (Petrilli et al., 1984) et de chamelle (Beg et al., 1986), il est à noter qu'ils sont également présents dans la séquence des deux principales protéines du lactosérum : l' $\alpha$-lactalbumine de la $\beta$-lactoglobuline (Fig. 3). 
Le résidu Tyr en position N-terminale permettrait l'interaction préférentielle avec les récepteurs $\mu$ du cerveau, surtout présents au niveau de l'hypothalamus et du thalamus (Teschemacher, 1987b; Paroli, 1988). Ces récepteurs interviennent lors de l'analgésie supraspinale, du relargage de prolactine èt de l'acétylcholine, dans la régulation de la motricité intestinale. La présence d'un résidu Arg en position $\mathrm{N}$ terminale devant une Tyr favoriserait au contraire les interactions avec les récepteurs $\delta$ (Chiba \& Yoshikawa, 1986) localisés dans la moelle épinière et dans le

\section{PEPTIDES OPIACES ISSUS DES PROTEINES DU LAIT}

\section{PEPTIDES AGONISTES}

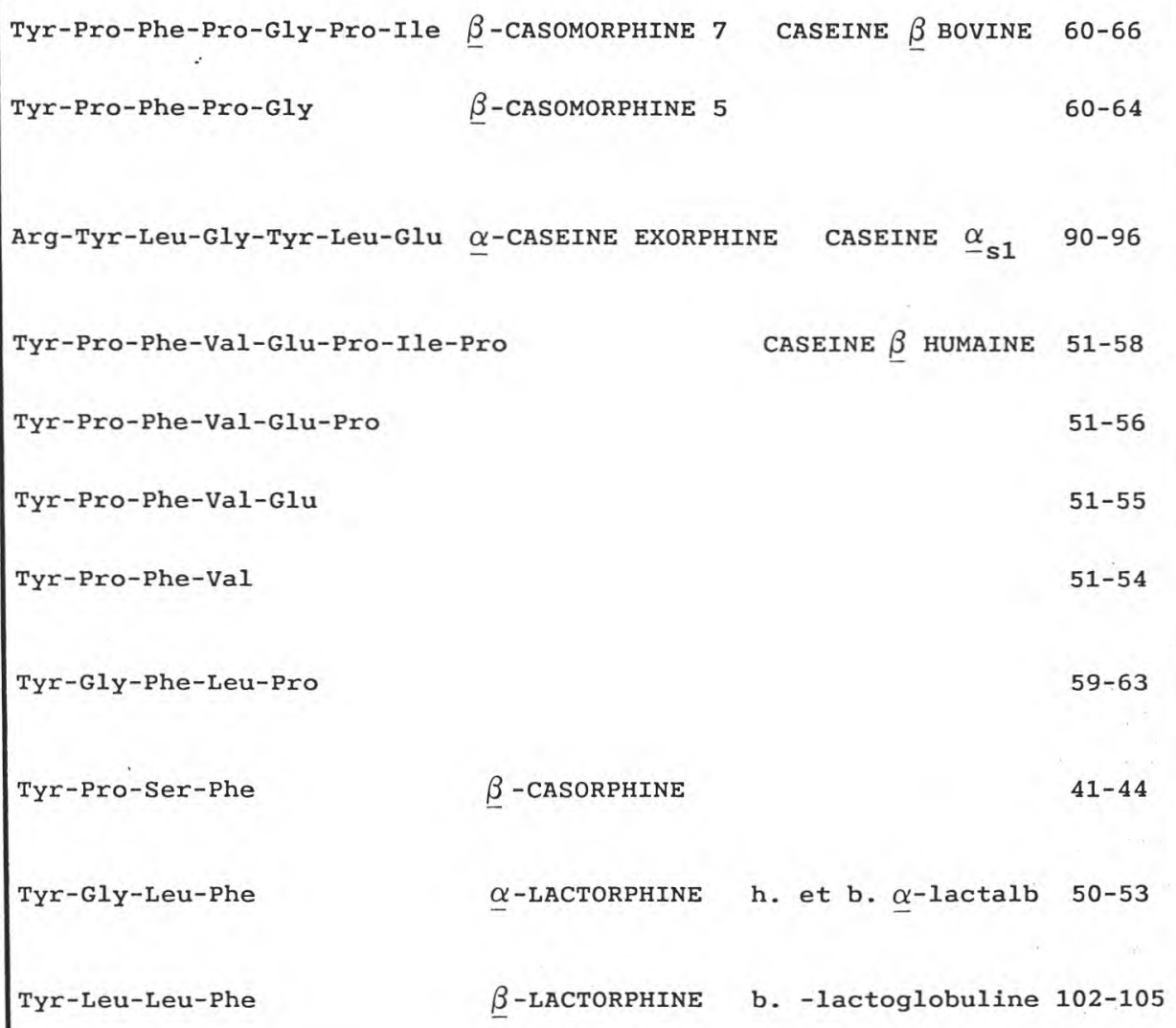

\section{ORIGINES}

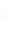


système limbique, sièges des sensations émotionnelles et des réflexes de mémorisation acquise (récompense et punition).

La présence d'exorphines issues de la caséine $\alpha_{s}$ et de $\beta$-casomorphines a été détectée par immunochimie dans le duodénum de mini-porc ayant ingéré de la caséine (Miesel, 1986) et dans l'intestin grêle d'hommes adultes ayant consommé du lait (Svedberg et al., 1985). Aucun composé réagissant avec des anti-exorphines n'a été trouvé à ce jour dans le plasma sanguin des mammifères adultes. Cela peut être dû à un problème de sensibilité, mais, au-delà de ceci, I'hypothèse suivante peut être formulée : ces peptides n'agiraient qu'au seul niveau de la paroi intestinale, probablement du côté séreux, en déclenchant la secrétion d'un messager biochimique de type hormonal, avant d'être dégradés. En revanche, un précurseur de la $\beta$-casomorphine 7 a été détecté dans le plasma des veaux nouveaunés (Umbach et al., 1985). De même, des structures voisines mais de poids moléculaires plus élevés que celui des B-casomorphines 6 et 7 ont été trouvées par immunochimie dans des échantillons de plasma sanguin prélevés chez des femmes enceintes ou allaitantes, alors que ces réactions étaient négatives avec le plasma prélevé chez les hommes et chez les femmes non enceintes utilisés comme témoins (Koch et al. 1988). Contrairement aux $\beta$-casomorphines, ces composés étaient résistants aux protéases du plasma.

Enfin, un composé proche de la $B$ casomorphine a été mis en évidence dans le plasma sanguin de plusieurs femmes souffrant de psychose post-partum (Lindstrom et al. , 1984).

A partir de cet ensemble d'observations, Teschemacher (1987 a et b) a postulé que les $\beta$-casomorphines participeraient à la régulation endocrine de la grossesse et de l'activité sécrétoire de la glande mammaire en modulant la libération d'ocytocine et de prolactine. Cette hypothèse suppose évidemment que la caséine $\beta$ produite par les cellules mammaires, ou un fragment de cette molécule contenant la $\beta$-casomorphine, soit transférée dans la circulation sanguine au cours de la lactogénèse. Or, de tels tranferts, des cellules mammaires vers le sang, ont déjà été mis en évidence pour l' $\alpha$-lactalbumine (Martin et al., 1980) et pour la caséine K (Woods et al., 1977; Zangerle et al., 1978). L'hypothèse de Teschemacher prend également en compte laugmentation du taux de prolactine plasmatique constatée chez des rats auxquels avait été injectée, par voie systémique, de la $\beta$ casomorphine (Nedvisdkova et al., 1985). II apparaît donc que, lors des modifications physiologiques de l'organisme qui accompagnent la grossesse et, par extension, la reproduction des mammifères, il y ait, en quelque sorte, suppléance ou renforcement des opiates endogènes du cerveau par des composants à activité morphino-mimétiques sécrétés par la glande mammaire.

A partir d'expérimentations menées chez des chiens avec les différentes Bcasomorphines, il a été mis en évidence un mécanisme complexe de régulation de l'appétit et de la prise de nourriture dans lequel intervenaient ces exorphines en opposition avec les endorphines (Paroli, 1988). Un repas d'épreuve apportant du saccharose et additionné de $\beta$-casomorphines ou seulement de caséopeptone multipliait le taux d'insuline plasmatique par un facteur 6 ou 7 , comparé aux taux observés lors de la prise d'un repas apportant seulement du saccharose (Nieter et Schatz, 1981; Nieter et al., 1981). Des repas similaires, à l'occasion desquels la caséopeptone était remplacée par du lait frais, provoquaient l'apparition, dans le plasma sanguin, de quantités 
significatives d'un composant réagissant avec une antisomatostatine (Schusdziarra et al., 1983a). L'accroissement postprandial d'insuline et de somatostatine était supprimé si de la naloxone, inhibiteur spécifique des opioïdes, était ajoutée au repas ou bien si des endorphines telles que la Leu et la Met-enképhaline étaient injectées par voie intraveineuse (Schusdziarra et al., 1983b). Ces résultats suggèrent que les endorphines pourraient moduler l'activité endocrine du pancréas.

L'activité analgésique des exorphines provenant de la caséine $\beta$ a été très largement étudiée. Sur la base du test «dit» du retrait de la queue des souris après pincement, l'injection intracérébroventriculaire des différentes $\beta$-casomorphines a permis de quantifier leur activité antidouleur, non seulement entre elles, mais aussi par rapport à la morphine. Par exemple, la $\beta$ casomorphine $1-5$ est de 10 à 20 fois moins active que la morphine (Brantl et al., 1981), bien qu'il suffise de 0,06 à $2 \mu$ mole par rat pour obtenir un effet analgésique appréciable; en revanche, la $\beta$ casomorphine 1-4 $\mathrm{NH}_{2}$, appelée encore morphiceptine, modifiée par substitution des acinés $L$ par position 2 et 4 par des acides aminés $D$ ou par de l'acide $D$ pipécolique serait 10 fois plus active que la morphine (Chang et al., 1982). La formation au niveau de l'intestin grêle de la morphiceptine semble hautement probable, puisqu'une réaction positive $\in: i t$ observée avec un anticorps spécifique et que des enzymes d'amidation existent dans le tractus gastro-intestinal et dans le suc pancréatique (Chang et al., 1985). Le transfert à l'homme des observations faites chez le rat est loin d'être évident, mais peut-être est-il permis de relier l'effet analgésique des exorphines laitières aux observations faites quotidiennement sur le comportement après tétée ou après absorption de biberon des nouveau-nés. Le calme et l'induction du sommeil post- prandiaux peuvent tout à fait résulter de la formation intestinale d'exorphines. Une conclusion semblable est formulée par Sturner \& Chang (1988), qui ont rapproché le contenu très élevé en $\beta$-casomorphine (9 $500 \mathrm{nmole} / \mathrm{g}$ ) et en morphiceptine $(1,4$ nmole/g) des laits infantiles prédigérés à la réduction significative des pleurs et l'accroissement du sommeil chez les enfants recevant ces laits. Sur un tout autre plan, faute de méthodologies extrapolables à l'homme, il serait purement spéculatif de formuler des hypothèses quant à l'existence ou la non existence de comportements de dépendance ou d'accoutumance aux exorphines laitières, comme cela est constaté pour la morphine. Mais à ce jour, aucune dépendance au lait n'a été décrite...!

Les résultats décrits dans la littérature, en ce qui concerne l'effet des $\beta$-casomorphines sur la motricité gastro-intestinale, sont contradictoires. Selon l'animal choisi comme modèle, il n'a été observé aucun effet chez le chat (Wienbeck et al., 1985), une suspension temporaire et réversible de l'activité péristaltique (iléon isolé du cobaye : Kromer et al., 1980) ou un accroissement des contractions de l'intestin grêle chez le chien (Burks et al., 1982). L'autre action connue des opiacés sur les fonctions intestinales est leur effet sur le transport des électrolytes à ce niveau. Des données particulièrement significatives quant aux éventuelles activités des exorphines du lait sur ces mécanismes ont été apportées par Hautefeuille et al. (1986) et Tomé et al. (1987). A partir d'expérimentations effectuées in vitro sur l'iléon de lapin, il a été mis en évidence que les $\beta$-casomorphines naturelles et leurs analogues augmentaient, comme les enképhalines, l'absorption des électrolytes et avaient, de ce fait, une action antidiarrhéique potentielle. Toutefois, cet effet physiologique des $\beta$-casomorphines naturelles ( $\beta$-casomorphine 1-5 ou morphicep- 
tine) n'était observé que si elles étaient ajoutées du côté séreux de l'iléon, alors qu'il était obtenu avec des analogues, dans lesquels les résidus proline étaient substitués par des D-alanine, aussi bien lors d'adjonctions du côté séreux que du côté luminal. Ces résultats ont permis d'affirmer l'existence non seulement de récepteurs des $\beta$-casomorphines du côté sereux de la muqueuse intestinale, mais ils accréditent aussi l'hypothèse selon laquelle il existerait un mécanisme de régulation dont une des facettes serait la dégradation transépithéliale des $\beta$-casomorphines naturelles. Mahé et al. (1988) ont montré que cette dégradation était principalement l'œuvre de la dipeptidylpeptidase IV. En effet, le blocage de l'activité de cette enzyme par le di-isopropylfluorophosphate (DFP) permettait à de la morphiceptine placée du côté luminal d'une chambre de Ussing de réduire le courant de court-circuit et de stimuler l'absorption des ions $\mathrm{Na}^{+}$et $\mathrm{Cl}$. La question qui se pose à la suite de ces résultats est évidemment celle de la nature de l'analogue du DFP présent dans les hydrolysats de caséine $\beta$ ou d'autres caséines, à même d'inhiber l'activité transépithéliale de la dipeptidylpeptidase IV. Les derniers résultats acquis par Tomé et al. (1988) montrent, en effet, que les récepteurs des casomorphines naturelles ou de leurs analogues sont problablement situés dans les neurones sous-muqueux, ce qui exige l'absorption de ces composés dans leur intégrité. Une telle localisation des récepteurs amène à formuler l'hypothèse selon laquelle l'activité anti-sécrétoire et anti-diarrhéique des casomorphines serait indirecte et donc neuromédiée. L'inhibition de cette activité constatée par Tomé et al. (1988) lorsqu'il y avait adjonction de composés bloquant la transmission nerveuse (tetrodoxine - épinédrine) appuie fortement cette hypothèse.
La figure 4 rassemble les différents effets physiologiques mis en évidence pour les opiopeptides endogènes. A prio$r i$, rien ne s'oppose à ce que les exorphines laitières aient l'ensemble de ces activités. Mais l'affirmer relèverait de la pure spéculation. De nombreuses expérimentations sont nécessaires, à l'aide de modèles prenant en compte autant que faire se peut la complexité des mécanismes physiologiques, et notamment la transmission en cascade des messages biochimiques au travers des différentes barrières (intestin - sang - cerveau), l'existence de valeurs seuils au-delà desquelles les réponses observées peuvent être l'inverse de celles attendues et la possible présence, dans une même macromolécule ou dans un même groupe de molécules, de fragments ayant une activité physiologique antagoniste. Chiba et Yoshikawa (1986) ont ainsi montré que la séquence 33-38 de la caséine $K$, appelée par eux casoxine, avait une activité antagoniste des opiacés. II n'en reste pas moins que la découverte de Brantl et al. (1979) a ouvert un nouveau champ passionnant de recherches et d'applications des opiopeptides en physiologie et en pharmacologie.

\section{Peptides à activité antihypertensive}

L'hypertension serait, selon Laragh (1979), la plus grande cause de maladie et de décès chez l'homme des pays industrialisés. Près de $30 \%$ de la mortalité chez l'humain adulte serait due à cette maladie ou à ses complications rénales, cardiaques ou cérébrales.

Les travaux menés par l'équipe de Laragh ont permis de démontrer que la vasoconstriction et le volume des liquides extracellulaires étaient sous la dépendance d'un système biologique cohérent, 
mettant en oeuvre les reins, le sang et les glandes surrénales par l'intermédiaire de la rénine, de l'angiotensine et de l'aldostérone. Lorsque la pression artérielle diminue sous l'effet d'un état de choc, d'une hémorragie ou de toute autre cause, de la rénine est sécrétée par le rein. Cette rénine va agir sur une protéine plasmatique fabriquée par le foie et libérer ainsi un décapeptide : l'angiotensine I. L'angioten-

\section{EFEETS PHYSIOLOGIQUES DES PEPTIDES OPIOIDES}

\section{EFFETS CENTRAUX}

1. ANALGESIE

2. CAtALEPSie

3. SEDATION ET TORPEUR

4. DEPRESSION RESPIRATOIRE

5. HYPOTENSION

6. THERMOREGULATION

7. REGULATION DE LA PRISE ALIMENTAIRE

8. SUPPRESSION DE LA SECRETION GASTRIQUE

9. AUGMENTATION DES TAUX DE GH, PRL ET ADH

10. DIMINUTION DES TAUX DE LH, FSH, TSH ET ACTH

11. REGULATION DU COMPORTEMENT SEXUEL

\section{EFEETS PERIPHERIQUES}

1. SUPPRESSION DE LA MOTRICITE INTESTINALE

2. POTENTIALISATION DE L'ACTIVITE DU MSH

Fig. 4. Effets physiologiques potentiels des peptides opiacés (Chiba et al., 1986). 
sine I est inactive, mais elle est hydrolysée en un octapeptide, l'angiotensine II, par une peptidase présente dans les poumons, le plasma et de nombreux autres tissus : I'Angiotensin Converting Enzyme ou ACE (E.C.3.4.15.1) (Fig. 5). Cette angiotensine II est le plus puissant vasoconstricteur connu. Sa présence entraîne une constriction rapide des artérioles et donc une remontée rapide de la pression artérielle. Mais l'action de l'angiotensine II est double, elle stimule également la

\section{SYSTEME RENINE ANGIOTENSINE}

\section{ANGIOTENSINOGENE}

RENINE

ACE

ANGIOTENSINE I

[10 AA peu active
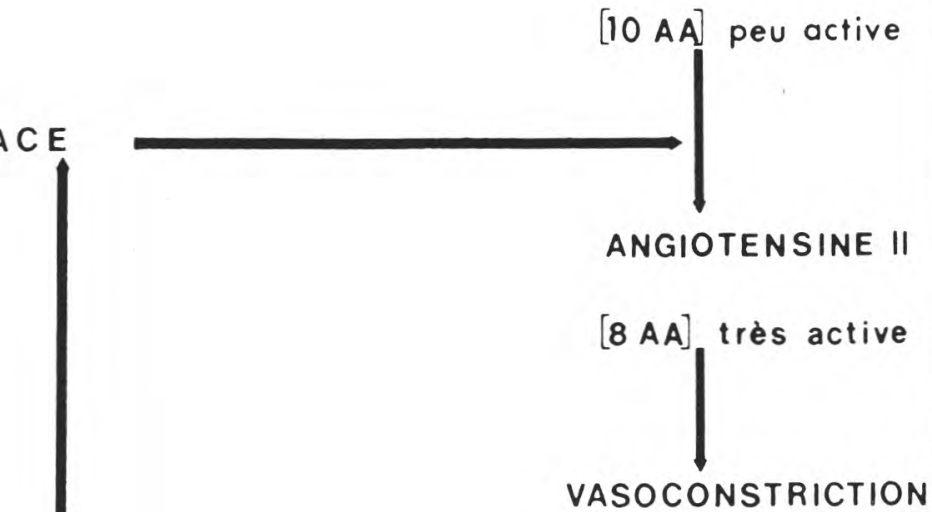

Exemple d'inhibiteurs

HYPERTENSION

SQ 14225 Captopril Squibb

HS $-\mathrm{CH}_{2}-\underset{\mathrm{C}_{3}^{\prime}}{\mathrm{C}} \mathrm{H}-\mathrm{CO}-\mathrm{N}-\mathrm{CH}-\mathrm{COOH}$

Caséine $\beta$ [7AA] $177-183$

Ala-Val-Pro-Tyr-Pro-Gln-Arg

Fig. 5. Schéma d'inhibition de l'ACE dans le système rénine -angiotensine. 
sécrétion d'aldostérone, ce qui entraîne au niveau des reins une accumulation de sodium et une excrétion du potassium. L'accumulation du sodium s'accompagne obligatoirement d'une rétention de l'eau, ce qui va accroître les volumes extra-cellulaires, donc le débit sanguin et par voie de conséquence la pression artérielle et la neutralisation de la production de rénine. Cette production de rénine est également stoppée lorsqu'une cause inverse provoque une augmentation de pression ou du débit sanguin. Le mécanisme décrit suppose l'existence de capteurs et de signaux de transmission. II a été effectivement démontré la présence de deux capteurs : l'un sensible à la pression, dit barorécepteur, situé dans les artérioles arrivant au rein, et l'autre sensible à la concentration en sodium dans les tubules. La transmission du signal des capteurs aux cellules sécrétant la rénine est assurée quant à elle par un neuromédiateur : la noradrénaline.

La mise au clair de ce mécanisme a conduit à rechercher des inhibiteurs de I'ACE, la dipeptidylcarboxypeptidase réalisant la transformation de l'angiotensine I en angiotensine II. Les molécules les plus efficaces se sont avérées être des peptides leurres (Bravo \& Tarazi, 1979) mis en évidence dans le venin d'un serpent brésilien (Ferreira et al., 1970).

L'examen systématique des séquences de ces peptides inhibiteurs ayant montré qu'ils avaient tout l'enchaînement Pro-Pro, Ala-Pro ou Ala-Hyp à leur $\mathrm{COOH}$ terminal, Maruyama et Suzuki (1982) ont recherché l'existence d'un tel enchaînement dans les peptides issus de l'hydrolyse trypsique de la caséine, protéine particulièrement riche en proline. A l'aide de 2 tests in vitro basés sur l'inactivation de la bradykinine (composé vasodilatateur provoquant également les contractions de I'utérus de rate et de l'iléon de rat) par l'ACE, cette équipe (Maruyama et al., 1985a) a identifié 3 séquences peptidiques inhibitrices de I'ACE. La première qualifiée, $\mathrm{CEI}_{12}$, avec l'enchaînement :

Phe-Phe-Val-Ala-Pro-Phe-Pro-Glu-ValPhe-Gly-Lys

est le segment 23-34 de la caséine $\alpha_{\mathrm{s} 1}$.

La deuxième, qualifiée $\mathrm{CEI}_{5}$, avec l'enchaînement :

\section{Phe-Phe-Val-Ala-Pro}

dérive de la précédente par action d'une proline endopeptidase de Flavobacterium meningosepticum.

La troisième, qualifiée $\mathrm{CEI} \mathrm{B}_{7}$, avec un enchaînement $C$ terminal différent, soit :

Ala-Val-Pro-Tyr-Pro-GIn-Arg est le segment 177-183 de la caséine $\beta$.

L'activité des séquences isolées se classait comme suit : $\mathrm{CEI}_{5}>\mathrm{CEl} \mathrm{B}_{7}>$ $\mathrm{CEI}_{12}$, à partir de l'ensemble des tests in vitro réalisés. La potentialisation d'activation de la bradykinine du $\mathrm{CEI}_{5}$ était 13 fois plus élevée que celle du $\mathrm{CEI}_{12}$. Toutefois, l'activité de ce dernier peptide est accrue par la présence de $\mathrm{Zn}^{++}$en concentration supérieure à $5 \mu$ moles (Maruyama et al., 1985b). La mesure in vivo de l'activité antihypertensive sur rats anesthésiés ayant reçu $10 \mathrm{mg} / \mathrm{kg}$ d'angiotensine I montrait que la pression artérielle était rétablie à son niveau normal lorsque 14,2 mg de $\mathrm{CEI}_{12}$ par $\mathrm{kg}$ étaient injectés par voie intraveineuse, soit 14,2 fois plus que lorsque du captopril (mercaptoalanyl-proline) était injecté par la même voie (Maruyama et al., 1987).

L'efficacité de l'adminstration orale d'inhibiteurs de I'ACE dans le traitement de l'hypertension a amené à rechercher la présence éventuelle de cette enzyme au niveau de l'intestin. Par immunochimie, elle a été localisée à la surface des microvillosités des cellules épithéliales de l'intestin grêle (jéjunum) (Stevens et al., 1988). 
Ainsi, les peptides à activité antihypertensive libérés lors de la dégradation digestive des protéines alimentaires sont à même d'interagir directement avec leur récepteur spécifique. Mais une telle localisation de l'ACE, jointe à sa spécificité d'hydrolyse (libération de dipeptides à partir de l'extrémité C-terminale des chaînes peptidiques) et à sa capacité de dégradation connue des enképhalines et de la bradykinine (Stevens et al., 1988), conduit à envisager que cette enzyme pourrait avoir de nombreux autres rôles physiologiques.

\section{Peptides à activité immunomodulante}

De nombreux facteurs présents dans le lait et surtout dans le colostrum aident le nouveau-né, dont le système immunitaire est immature, à se défendre contre les infections virales et bactériennes. Cette défense fait intervenir non seulement les immunoglobulines : $\lg A s, \lg M$ et $\operatorname{lgG}$, mais également des enzymes: lysozyme - lactoperoxydase, et des protéines ferriprivatives: lactoferrine et transferrine. Un rôle majeur a même été attribué à ces dernières protéines dans les mécanismes anti-infectieux présents dans l'intestin du nourrisson; elles potentialiseraient l'action des IgAs et du lysozyme et elles inhiberaient le développement bactérien contaminant par ferriprivation et, aussi, en inhibant l'adhésion des cellules en formant un complexe avec les glycopeptides des parois (Spik, 1988). Toutefois, à notre connaissance, démonstration n'a pas été faite, à ce jour, d'une action bactériostatique in vivo de la lactoferrine et de la sérotransferrine. Sur un autre plan, il est connu que les bifidobactéries prédominent dans le tractus intestinal des enfants nourris au sein, que ces micro-organismes exercent un effet de barrière per- missif vis-à-vis de E. coli (Raibaud \& Ducluzeau, 1984) et que les enfants ainsi nourris sont sensiblement moins atteints de maladies gastro-intestinales que ceux nourris au lait bovin. Aussi a-t-on recherché les composants du lait maternel à l'origine de ce développement explosif des bifidobactéries. Bezkorovainy et al. (1981) ont les premiers montré que le facteur de croissance du Bifidus était un glycopeptide en provenance de la caséine du lait maternel. Avec le progrès des techniques séparatives, Azuma et al. (1984) ont préparé le glycomacropeptide (GMP) de la caséine $K$ humaine et démontré la très haute efficacité de ce composant sur la croissance de la souche Bifidobacterium infantis $\mathrm{s}_{12}$ (le GMP est, en effet, actif à des doses de $50 \mathrm{ppm}$ !). La réduction drastique de l'activité constatée après hydrolyse pepsique prolongée ou après action de la pronase indique que l'intégralité des séquences peptidique et glucidique du GMP est nécessaire pour la liaison avec le récepteur bactérien. Au cours de cette étude, il a été également montré que le GMP bovin avait une activité 4 fois plus faible.

A ces facteurs de défense d'origine protéique du nouveau-né s'ajoutent ceux en provenance des cellules de l'organisme : macrophages, granulocytes, lymphocytes $T$ à médiation cellulaire et lymphocytes $B$ à médiation humorale. La colostrum et le lait humains contiennent, en effet, des quantités élevées de leucocytes (de 1 à 10 millions/ml dans les premiers jours, teneur qui s'abaissent ensuite à $2000-4000 / \mathrm{ml}$ ) (Lestradet, 1988), dont 80 à $90 \%$ sont des macrophages (Pitt et al., 1974) et 10 à $20 \%$ des lymplocytes $T$, qui fabriquent de l'inferféron et des lymphocytes $B$ à même de traverser la muqueuse intestinale et de sécréter ensuite des immunoglobulines $G$ (Lestradet, 1988). 
Par analogie avec les activités immunomodulantes de peptides produits par les bactéries, Parker et al. (1984) se sont posé la question de l'éventuelle existence dans le premier aliment de l'être humain, à savoir le lait, de fractions d'activité similaire. Leur démarche très finaliste s'appuyait sur le constat de la résistance aux infections bactériennes du nouveau-né nourri au sein, à travers les âges, avant tout développement de la pharmacothérapie. A l'aide de deux tests in vitro : la sécrétion d'anticorps hémolytiques contre les hématies de mouton par les cellules de la rate de souris - la phagocytose des hématies de mouton par les macrophages des cellules péritonéales de la souris, ils ont mis en évidence une activité immunostimulante dans l'hydrolysat enzymatique de caséine humaine. Le peptide responsable a été purifié et identifié. II s'agissait de la séquence :

$$
\text { Val-Glu-Pro-Ile-Pro-Tyr }
$$

correspondant au segment 54-59 de la caséine $\beta$ humaine. Cette séquence a été synthétisée et administrée, parallèlement au peptide naturel, par voie intraveineuse à des souris adultes, à des doses de l'ordre de $0,5 \mathrm{mg} / \mathrm{kg}$. Les deux peptides augmentaient significativement la résistance à une infection par Klebsiella pneumoniae, (infection réalisée $24 \mathrm{~h}$ après l'administration du peptide) mais le peptide naturel était nettement plus efficace. II est à noter que la séquence $54-59$ se retrouve en grande partie dans la séquence à activité exorphique de la caséine $\beta$ humaine ( $\beta$-casomorphine 1-7) (Fig. 6). Par ailleurs, la même activité immunostimulante a été mise en évidence pour la séquence $63-68$ de la caséine $\beta$ bovine préalablement obtenue par synthèse chimique (Migliore-Samour et Jollès, 1988), à savoir :

$$
\text { Pro-Gly-Pro-lle-Pro-Asn }
$$

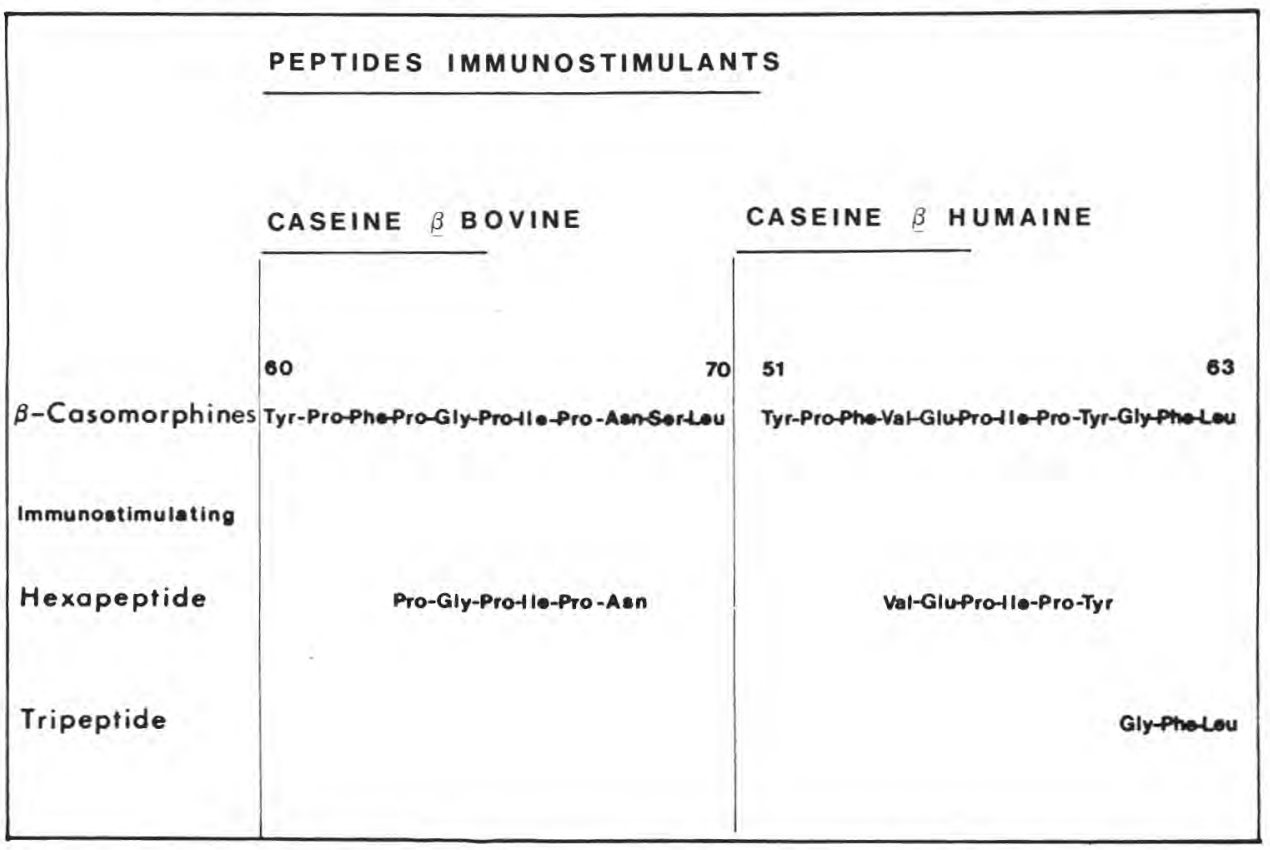

Fig. 6. Peptides immunomodulateurs dérivés des caséines B bovine et humaine (Migliore - Samour et Jollès, 1988). 
Aussi, en regard des activités opiacées et immunomodulantes rassemblées dans les segments $60-70$ de la caséine $\beta$ bovine et $51-63$ de la caséine $\beta$ humaine, Migliore-Samour et Jollès (1988) ont qualifié ces parties de molécules de caséines de "zones stratégiques" (Fig. 6).

L'existence, dans le tube digestif du nourrisson, des peptides 54-59 de la caséine $\beta$ humaine et 63-68 de la caséine $\beta$ bovine n'a pas été démontrée. Leur rôle in vivo reste encore une question ouverte. Potentialisent-ils, comme le propose l'équipe animée par Jollès, l'activité phagocytaire des macrophages vis-à-vis des bactéries entériques telles qu'E. coli ? Une telle action contribuerait évidemment à la mise en place de la flore bifidogène.

\section{Peptides à activité antithrombotique}

Les coagulations intravasculaires constituent une des causes les plus fréquentes de la mortalité de la population des pays industrialisés (Zucker, 1980). Les mécanismes intervenant dans la formation des thrombus veineux ou artériels sont sensiblement les mêmes (à l'exception de la cause initiale) que ceux intervenant lors de l'hémostase (arrêt du saignement). Lorsque la paroi d'un vaisseau sanguin est endommagée : coupure ou dégradation biochimique des cellules épithéliales relative aux multiples causes de l'athérosclérose (Zucker, 1980), il y a reconnaissance de l'endommagement par les plaquettes, qui sécrètent de la prostaglandine $\mathrm{H}_{2}$, rapidement transformée en thromboxane $A_{2}$. Cette dernière molécule est un stimulateur puissant de l'agrégation des plaquettes aux fibres de collagène contenues dans le sous-endothélium. II se forme alors le «clou plaquettaire» (Caen, 1977), première phase de l'obturation de la coupure ou de la formation du thrombus. Ce mécanisme initial est suivi d'une série de réactions conduisant simultanément à la transformation de la prothrombine plasmatique en thrombine et à la sécrétion d'ADP par les granules présents à la surface des plaquettes, ce qui, non seulement stimule leur agrégation, mais induit également l'apparition, au niveau de la membrane, de récepteurs spécifiques du fibrinogène (Zucker, 1980). La liaison de la molécule de fibrinogène avec ces récepteurs, constitués par des glycoprotéines, nécessite la présence d'ions calcium et se fait avec le segment 400-411 de la chaîne $\gamma$ du fibrinogène (Kloczewiak et al., 1984). Le fibrinogène ainsi lié aux plaquettes est hydrolysé en fibrine insoluble par la thrombine, ce qui constitue la phase finale de la coagulation du sang.

La similitude des phénomènes de coagulation du sang et du lait a conduit Jollès et al. (1986) à rechercher les homologies de séquence pouvant exister entre les molécules de fibrinogène humain et de la caséine $\mathrm{K}$ bovine.

L'homologie trouvée entre la partie $\mathrm{N}$ terminale du caséinomacropeptide et le segment 400-411 de la chaîne $\gamma$ du fibrinogène a amené ces auteurs à formuler l'hypothèse selon laquelle le segment 106-116 du CMP bovin pourrait se fixer aux récepteurs plaquettaires du fibrinogène et bloquer ainsi la formation d'éventuels thrombus. La validité de cette hypothèse a été démontrée à l'aide de 2 tests in vitro: suivi de l'agrégation plaquettaire à l'aide d'un agrégomètre - suivi de l'inhibition de la fixation du fibrinogène marqué à 1251 aux récepteurs plaquettaires. Le segment 106-116, isolé d'un hydrolysat trypsique du CMP bovin et purifié par chromatographie, s'est révélé à la fois nettement plus actif dans ces 2 tests que le peptide homologue obtenu par synthè- 
se chimique et, aussi, plus inhibiteur que le peptide $400-411$, isolé de la chaîne $\gamma$ du fibrinogène humain, dans la fixation de cette molécule entière aux récepteurs plaquettaires. En revanche, cette activité de peptides leurres des récepteurs plaquettaires semble requérir une conformation spatiale très précise, car ces mêmes auteurs ont noté que l'activité antithrombotique des peptides 106-112 et 113-116, dérivés de l'undécapeptide, était nettement plus faible que celle du segment complet.

\section{Peptide à activité de type bombésique}

La bombésine est un peptide de 14 acides aminés découvert par l'équipe d'Erspamer en 1971 dans la peau d'une grenouille commune en Europe : Bombinus bombina. Chez les mammifères, ce peptide influence le fonctionnement de l'appareil digestif en agissant sur la secrétion des hormones de la digestion. Par immunochimie, la présence de bombésine a été mise en évidence dans le tractus digestif, dans les poumons, mais aussi dans le cerveau. Injectée dans le cerveau de souris, la bombésine provoque une forte chute de la température corporelle, ce qui amène à lui attribuer un rôle majeur dans la thermorégulation.

Lazarus et al. (1986), par immunochimie, ont mis en évidence l'existence d'un peptide ayant une structure voisine de celle de la bombésine, dans les laits humain et bovin.

Le peptide bombésine-like n'a pas encore été isolé du lait. Existe-t-il dès la sécrétion ou est-ce un produit de dégrédation lié aux protéases naturelles du lait ? Son activité semble élevée, puisque les fractions isolées par Lazarus et al. sont en quantité suffisante pour intervenir sur le niveau plasmatique des hormones gastro-intestinales, les sécrétions gastriques et la sensation de satiété.

\section{LES VOIES DE SÉPARATION, DE PURI- FICATION ET DE FRAGMENTATION DES PROTÉINES LAITIERES}

La préparation, à partir du lait collecté par les entreprises, de produits enrichis en peptides ayant une utilisation diététique ou pharmacologique passe, sans conteste, par la séparation des différentes protéines du lait.

Les diverses possibilités de séparation, de purification et de fragmentation des deux grandes catégories de protéines laitières : les caséines et les protéines du lactosérum, encore appelées protéines solubles, ont été revues par Maubois (1984).

\section{Séparation, purification de la caséine entière du lait}

La caséine dite entière est la principale protéine du lait $(80 \%$ de la matière azotée protéique) : un litre de lait en contient 25 à $27 \mathrm{~g}$. Les procédés d'extraction et de purification actuellement utilisés reposent sur sa propriété d'insolubilisation à son $\mathrm{pH}$ isoélectrique ou sous l'effet de la présure. Ils conduisent à 3 catégories de produits commerciaux :

- les caséines lactiques, obtenues par acidification biologique du lait;

- les caséines acides, obtenues par addition de protons $\left(\mathrm{H}^{+}\right)$au lait;

- les caséines présure, obtenues par action enzymatique. 
Les caséines ainsi obtenues sont utilisées en l'état, à la fois pour leurs qualités nutritionnelles (biscuiterie - salaisonnerie - fromages fondus - aliments diététiques et infantiles) et pour leurs qualités technologiques (industrie des colles, des peintures, de la boutonnerie de luxe : galalithe). Mais leur principale destination est de servir de matière première à la fabrication des caséinates, c'est-à-dire de produits obtenus par neutralisation de la caséine acide ou lactique à l'aide d'une base (soude, chaux, potasse, ammoniaque) (Ségalen, 1982).

Les caséinates représentent, en effet, des matières premières alimentaires assez exceptionnelles dans le monde des protéines destinées à l'alimentation de l'homme. Ces produits sont obtenus aisément à l'échelle industrielle avec une grande pureté ( $97-98 \%$ de protéines sur sec; Ségalen, 1982). Leur composition en acides aminés est relativement équilibrée, quoique légèrement carencée en acides aminés soufrés. Ils ne comportent jamais de facteurs antinutritionnels, comme cela est quasiment toujours le cas avec les protéines végétales. Ils présentent des propriétés fonctionnelles particulièrement intéressantes pour les industries agro-alimentaires de seconde transformation; leurs capacités de structuration de l'eau et d'émulsification de la matière grasse sont pratiquement sans égales (Ségalen, 1982).

II existe une différence notable de taille entre les micelles de caséine en suspension dans le lait ( 30 à $300 \mathrm{~nm}$ ) et les protéines sériques (quelques $\mathrm{nm}$ ). Aussi était-il possible de penser a priori qu'une séparation basée sur la taille était réalisable. Cependant, les tentatives en ce sens s'étaient soldées par des échecs ou par des propositions difficilement extrapolables (Maubois, 1984). Le développement récent de nouvelles membranes de microfiltration, l'acquisition de la maîtrise de leur mise en œuvre, notamment au niveau des débits de recirculation et des différentiels de pression transmembranaire, permettent de penser que la séparation du phosphocaséinate natif à partir de lait écrémé deviendra possible à l'échelle industrielle (Fauquant et al., 1988). Outre les avantages technico-économiques résultant de la simplification de la technologie d'extraction, il est d'ores et déjà certain que le produit ainsi obtenu créera de nombreux débouchés à la caséine du lait, en raison de ses caractéristiques fonctionnelles (viscosité (Brulé et al., 1979) pouvoirs moussant, liant et émulsifiant) et diététiques (sa teneur en $\beta$-lactoglobuline est, en effet, très faible en regard de celle existant dans les caséinates du commerce; il devrait donc être a priori moins allergénique). Mais ce phosphocaséinate natif est également à même d'être une manière première de choix pour l'extraction ultérieure des segments phosphopeptidiques (cf. le paragraphe «Peptides intervenant dans la nutrition minérale") ou des caséines individuelles.

\section{Séparation des caséines individuelles}

Que ce soit pour la séparation des différentes caséines du lait $\alpha_{\mathrm{s} 1}, \alpha_{\mathrm{s} 2}, \beta$ et $\mathrm{K}$, que ce soit pour l'extraction des différentes protéines sériques, il nous apparaît nécessaire de souligner l'absolue nécessité de prendre en compte la valorisation, l'utilisation du ou des coproduits lors de la mise au point et du développement d'un procédé de séparation. II ne serait, en effet, guère admissible que ce ou ces coproduits soient dirigés vers la station d'épuration !

Parmi les caséines du lait, il est probable que c'est vers la caséine $\beta$ que va s'orienter l'essentiel des efforts de Recherche-Développement pour la mise 
au point de procédés de séparation et de purification, en raison de la richesse de cette caséine en segments peptidiques à activité physiologique : phosphopeptide $1-25$; $\beta$-casomorphine 60-66; peptide antihypertensif 177-183. La caséine $\beta$ est dominante dans le lait maternel et dans le lait de chèvre $(67 \%$ de la caséine entière contre $36 \%$ pour le lait de vache).

En mettant à profit la dépolymérisation à basse température de la caséine $\beta$, et les caractéristiques spécifiques de perméabilité et d'état de surface d'une nouvelle membrane minérale de microfiltration, notre groupe (Terré et al., 1986) a mis au point un procédé d'extraction et de purification de la caséine $\beta$ à même d'être extrapolé industriellement. Au minimum, 10 à $20 \mathrm{~g}$ de caséine $\beta_{2}$ pure à plus de $90 \%$ pourraient être obtenus par heure et par $\mathrm{m}^{2}$ de membrane. Quant aux coproduits, lait ou caséinates appauvris en caséine $\beta$ mais enrichis en caséine $\alpha_{\mathrm{s}}$, ils devraient avoir les mêmes utilisations que le lait ou les caséinates initialement mis en œuvre.

L'étude systématique de la cinétique d'hydrolyse trypsique de cette caséine $\beta$ sous l'effet des facteurs du milieu, étude combinée avec la mise en œuvre de la technologie des réacteurs enzymatiques à membrane, devrait permettre, à moyenne échéance, de préparer des solutions enrichies en chacun des 3 peptides évoqués ci-dessus (Léonil et al., 1988).

La séparation des autres caséines du lait ou de leurs fragments n'a pas, à notre connaissance, été décrite à ce jour, sauf en ce qui concerne le glycomacropeptide résultant de l'action de la chymosine sur la caséine K (Brulé et al., 1980). Rien ne s'oppose a priori à ce que l'extraction et la purification des segments peptidiques à activité exorphine (caséine $\alpha_{\mathrm{s}}$ ) ou antithrombotique (caséine $K$ ) soient réalisables selon une démarche technologique analogue à celle envisagée pour ceux présents dans la séquence de la caséine $\beta$.

\section{Séparation de l'ensemble des pro- téines du lactosérum}

Les concentrés de protéines de lactosérum ont, à la fois, d'excellentes propriétés fonctionnelles et une très haute valeur nutritionnelle. La comparaison avec les protéines de l'œuf et avec la protéine FAO de référence (Roger, 1979) montre que ces protéines ont une composition en acides aminés indispensables répondant à toutes les exigences de la nutrition humaine. De ce fait, elles sont de plus en plus considérées comme des protéines idéales pour la diététique humaine, que ce soit celle de l'enfant ou celle de l'adulte en détresse thérapeutique.

Les concentrés de protéines de lactosérum sont obtenus principalement selon la technologie d'ultrafiltration sur membrane, mais il existe d'autres techniques d'obtention basées sur la chromatographie d'échanges d'ions (procédés Sphérosil et Vistec) ou sur la filtration sur gel (procédé Pharmacia). Près de $80 \%$ du parc membranes d'ultrafiltration de l'industrie laitière mondiale sont consacrés au traitement du lactosérum, soit en 1987 certainement plus de $100000 \mathrm{~m}^{2}$; et la surface de ce parc croit de plus de $20 \%$ l'an, c'est dire combien cette technologie correspond aux besoins du secteur industriel concerné.

L'obtention de CPL à haute pureté, c'est-à-dire ayant un rapport $\mathrm{N} \times$ $6,38 /$ matière sèche supérieur à 0,80 , requis pour la préparation de produits à haut pouvoir moussant ou se prêtant aux opérations d'hydrolyse ménagée, se trouvait limitée du fait de la présence, dans les lactosérums produits industriellement, 
de matière grasse résiduelle en provenance de la membrane des globules gras du lait. Notre groupe (Maubois et al., 1987) a mis à profit les propriétés d'agrégation des phospholipoprotéines composant cette matière grasse, en présence de calcium ionisé et à température modérée, pour mettre au point un procédé de séparation qui a connu une extrapolation industrielle rapide. En effet, les CPL résultants ont des pouvoirs moussant et gélifiant très élevés. Ils sont totalement débactérisés et le coproduit, à savoir le concentré de phospholipoprotéines, a d'excellentes propriétés émulsifiantes, qui trouvent tout leur intérêt dans l'industrie de la salaison. De plus, ils se prêtent particulièrement bien à l'hydrolyse ménagée en réacteurs enzymatiques à membrane, pour la préparation des aliments de réanimation selon le procédé développé par Maubois et al. (1979). Un tel procédé permet, en effet, de simuler la digestion protéique et d'apporter à l'organisme de patients en situation de détresse (cancéreux de voies digestives - reséqués de l'intestin grêle) les nutriments nécessaires à leur survie. Les peptides quittant le réacteur sont absorbés de façon optimale et totale par la muqueuse intestinale. La production de ces peptides, développée par la société Sopharga, a atteint en 1987 plusieurs centaines de tonnes, ce qui a représenté un débouché très valorisant pour plus de 100 millions de litres de lactosérum.

\section{Séparation des protéines indivi- duelles du lactosérum}

L'application des techniques de séparation fine, telles que la chromatographie d'échange d'ions, aux CPL délipidés a permis la mise au point de procédés industriels d'extraction des protéines indi- viduelles du lactosérum, telles que le couple lactoferrine-lactoperoxydase, du fait du $\mathrm{pH}_{\mathrm{i}}$ très particulier de ces protéines.

La séparation des protéines majeures du lactosérum : $\beta$-lactoglobuline et $\alpha$-lactalbumine pourrait se faire par la mise à profit de la propriété de polymérisation réversible de l' $\alpha$-lactalbumine à bas $\mathrm{pH}$ sous l'effet d'un léger traitement thermique, propriété démontrée par Pearce (1983), selon la démarche technologique proposée par Maubois (1988). Outre son intérêt pour la préparation de laits humanisés et des peptides à activité physiologique contenus dans sa séquence, l' $\alpha$-lactalbumine pourrait être utilisée comme contraceptif local (Shur, 1984).

\section{CONCLUSIONS}

Bien qu'il soit le liquide alimentaire le mieux connu et le plus transformé, le lait reste encore une source particulièrement riche de nouveaux débouchés à haute valeur ajoutée. Les découvertes de la physiologie moderne conduisent à penser que beaucoup de molécules, parmi les 2000 qui le composent, ont un rôle biologique allant bien au-delà du simple apport de nutriments. Il y a là une chance à saisir par tous les acteurs concernés par la filière laitière : producteurs, transformateurs, chercheurs.

De nombreuses réponses doivent cependant être apportées par la recherche, avant que ne se mettent en place les stratégies industrielles de production et de commercialisation de produits dérivés du lait enrichis en tel ou tel peptide à activité physiologique. La première question à se poser est de savoir si économiquement la voie des peptides, 
dits naturels, est la bonne, si celle des peptides de synthèse ne serait pas plus intéressante. Bien que le consensus sur ce point soit loin d'être réalisé, il est reconnu que l'utilisation des peptides de synthèse exige une pureté très élevée, en raison des risques de toxicité liés aux solvants et substances chimiques utilisés pour les opérations de réalisation des liaisons peptidiques, ce qui signifie obligatoirement un coût élevé. Une telle pureté n'est pas exigible des peptides naturels si leur préparation a mis en œuvre des processus purement physiques ou physicochimiques et l'emploi d'enzymes physiologiques. Les contaminants de ces préparations "naturelles" risquent, au pire, d'avoir un rôle de nutriment. II semblerait, également, que pour des raisons liées à la présence d'isomères optiques ou de substances chimiques résiduelles inhibitrices, les peptides de synthèse aient une activité physiologique très nettement inférieure à celle des peptides naturels.

Diverses voies d'administration aux êtres humains de ces préparations peptidiques sont envisageables: si les voies parentérale et nasale requièrent obligatoirement la préparation de solutions de peptides, la voie orale pose, elle, de nombreux problèmes. Ne serait-il pas suffisant d'administrer des préparations enrichies en protéines-substrats en confiant, en quelque sorte, aux enzymes du tractus gastro-intestinal la libération des peptides recherchés? En cas de réponse négative cette question, faudra-t-il ou non protéger le ou les peptides pour le(s) soustraire à l'activité d'enzymes avant qu'ils atteignent leurs récepteurs?

Outre ces quelques questions recensées de façon non exhaustive, il devrait y avoir également un accroissement considérable des connaissances en physiologie humaine sur les mécanismes des réactions mettant en jeu ces segments peptidiques, car les inconnues sont légion : nature des messages entre l'intestin, le sang, le cerveau, les retours vers les organes d'expression... Mais le défi est à la mesure des difficultés, dont quelques-unes sont seulement énoncées ici; n'a-t-on pas, en effet, d'ores et déjà prévu un marché mondial s'élevant entre 40 et 60 milliards de francs à l'horizon 1995 (Morre, 1988) ?

\section{RÉFÉRENCES}

Armbrecht H.J. \& Wasserman R.H. (1976) Enhancement of $\mathrm{Ca}^{++}$uptake by lactose in the rat small intestine. J. Nutr. 106, 1265-1271

Azuma N., Yamauchi K. \& Mitsuoka T. (1984) Bifidus growth-promoting activity of a glycomacropeptide derived from human K-casein. Agric. Biol. Chem. 48, 2159-2162

Beg O.V., Von Bahr-Lindstrom H., Zaidi S.H. \& Jornvall $H$. (1986) Characterization of a camel milk protein rich in proline identifies a new $\beta$ casein fragment. Regul. Peptides 15, 55-62

Bezkorovainy A. \& Topouzian N. (1981) Bifidobacterium bifidus var. pennsylvanicus growthpromoting activity of human milk casein and its derivatives. Int. J. Biochem. 13, 585-590

Brantl V., Teschemacher H., Henschen A. \& Lottspeich F. (1979) Novel opioid peptides derived from casein ( $\beta$ casomorphins). HoppeSeyler's Z. Physiol. Chem. 360, 1211-1216

Brantl V., Teschemacher H., Henschen A. \& Lottspeich F. (1981) Opioid activities of B-casomorphins. Life Sci. 28, 1903-1909

Bravo E.L. \& Tarazi R.C. (1979) Converting enzyme inhibition with an orally active compound in hypertensive man. Hypertension 1 , 39-46

Brulé G. \& Lenoir J. (1987) La coagulation du lait. In : Le Fromage (Eck A., ed.). Technique et Documentation, Lavoisier, Paris, pp. 1-20

Brulé G., Fauquant J. \& Maubois J.L. (1979) Preparation of "native" phosphocaseinate by combining membrane ultrafiltration and ultracentrifugation. J. Dairy Sci. 62, 869-875

Brulé G. Roger L., Fauquant J. \& Piot M. (1980) Procédé de traitement d'une matière à base de caséine contenant des phosphocaséi- 
nates de cations monovalents et leurs dérivés. Produits obtenus et applications. Brevet Fr. $n^{\circ} 8002281$

Burks T.F., Hirning L.D.r Galligan J.J. \& Davis T. (1982) Motility effects of opioid peptides in dog intestines. Life Sci. 31, 2237-2240

Caen J. (1977) Les plaquettes sanguines. Recherche 80, 624-630

Chang K.J., Cuatrecasas P., Wei E.T. \& Chang J.K. (1982) Analgesic activity of intracerebroventricular administration of morphiceptin and $\beta$-casomorphins : correlation with the morphine $(\mu)$ receptor binding affinity. Life Sci. 30,1547 1551

Chang K.J., Su Y.F., Brent D.A. \& Hang J.K (1985) Isolation of a specific $\mu$ opiate receptor peptide morphiceptin, from an enzymatic digest of milk proteins. J. Biol. Chem. 260, 9706-9712

Chiba H. \& Yoshikawa M. (1986) Biologically functional peptides from food proteins : new opioid peptides from milk proteins. In : Protein Tailoring for Food and Medical Uses (Feeney R.E. \& Whitaker J.R., eds). Marcel Dekker, New York, pp. 123-153

Dupuis Y., Digaud A. \& Fournier P. (1978) Phosphatases alcalines intestinales et composés glucidiques dans leurs rapports avec l'absorption du calcium. Ann. Biol. Anim. Biochim. Biophys. 18, 1129-1139

Fauquant J., Maubois J.L. \& Pierre A. (1988) Microfiltration du lait sur membrane minérale. Tech. Lait 1028, 21-23

Ferreira S.H., Bartelt D.C. \& Greene L.J. (1970) Isolation of bradykinin-potentiating peptides from Bothrops jararaca venom. Biochemistry 9, 2583-2593

Gerber H.W. \& Jost R. (1986) Casein phosphopeptides : their effect on calcification of in vitro cultured embryonic rat bone. Calcif. Tissue Int. 38, 350-357

Hambraeus L. (1985) Importance of milk proteins in human nutrition : physiological aspects. In : Milk Proteins'84. Pudoc, Wageningen, pp. 63-79

Hautefeuille M., Brantl V., Dumontier A.M. \& Desjeux J.F. (1986) In vitro effects of $\beta$-casomorphins on ion transport in rabbit ileum. Am. J. Physiol. : Gastrointest. Liver Physiol. 250, G92-G97

Henschen A., Lottspeich F., Brantl V. \& Teschemacher H. (1979) Novel opioid peptides derived from casein ( $\beta$-casomorphins). II. Structure of active components from bovine casein peptone. Hoppe-Seyler's Z. Physiol. Chem. 360, 1217-1224
Jollès P., Levy-Toledano S., Fiat A.M., Soria C., Gillessen D., Thamaidis A., Dunn F.W. \& Caen J.P. (1986) Analogy between fibrinogen and casein. Effect of an undecapeptide isolated from $\mathrm{K}$ casein on platelet function. Eur. J. Biochem. 158, 379-382

Klee W.A., Zioudrou C. \& Streaty R.A. (1978) Exorphins peptides with opioid activity isolated from wheat gluten and their possible role in the etiology of schizophrenia. In : Endorphins in Mental Health Research (Usdin E., Bunney W.E. \& Kline N.S., eds). MacMillan, New York, pp. 209-218

Kloczewiak M., Timmons S., Lukas T.J. \& Hawiger J. (1984) Platelet receptor recognition site on human fibrinogen. Synthesis and structure-function relationship of peptides corresponding to the carboxy-terminal segment of the chain. Biochemistry 23, 1767-1774

Koch G., Wiedemann K., Drebes E., Zimmermann W., Tink G. \& Teschemacher H. (1988) Human $\beta$-casomorphin-8 immunoreactive materials in the plasma of women during pregnancy and after delivery. Regul. Peptides 20, 107-117

Kocian J. (1986) Lactose intolerance. 3. Its complications. Cs. Gastroenterol. Vyz. 40, 252257

Korycka-Dahl M. \& Richardson T. (1980) Initiation of oxidative changes in foods. J. Dairy Sci. $63,1181-1198$

Kromer W., Pretzlaff W. \& Wornoff R. (1980) Opioids modulate periodicity rather than efficacy of peristaltic waves in the guinea pig ileum in vitro. Life Sci. 26, 1857-1865

Laragh J.M. (1979) L'hypertension. Recherche 105, 1068-1076

Lazarus L.H., Gaudino G., Wilson W.E. \& Erspamer V. (1986) An immunoreactive peptide in milk contains bombesin-like bioactivity. Experientia 42, 822-823

Lee Y.S., Noguchi T. \& Naito H. (1979a) An enhanced intestinal absorption of calcium in the rat directly attributed to dietary casein. Agric. Biol. Chem. 43, 2009-2011

Lee Y.S., Naguchi T. \& Naito H. (1979b) Abstracts of papers. Annu. Meeting of Food and Nutr. Soc. Japan, Tokyo, May, 41

Léonil J., Mollé D. \& Maubois J.L. (1988) Study of the early stages of tryptic hydrolysis of $\beta$-casein. Lait 68, 291-294

Lestradet H. (1988) Laits et immunité. Cah. Nutr. Diet. 23, 297-300 
Lindstrom L.H., Nyberg F., Terenius L., Bauer K., Besev G., Gunne L.M., Lyrenas S., Willdeck-Lund G. \& Lindberg B. (1984) CSF and plasma $\beta$-casomorphin-like opioid peptides in post partum psychosis. Am. J. Psychiatry 141, 1059-1066

Mahé S., Tomé D., Dumontier A.M. \& Desjeux J.F. (1988) Absorption of intact morphiceptine by diisopropylfluorophosphate-treated rabbit ileum. (Publication soumise)

Martin R.H., Glass M.R., Chapman C., Wilson G.D. \& Woods K.L. (1980) Human alpha-lactabumin and hormonal factors in pregnancy and lactation. Clin. Endocrinol. 13, 223-230

Maruyama S. \& Suzuki H. (1982) A peptide inhibitor of angiotensin I converting enzyme in the tryptic hydrolysate of casein. Agric. Biol. Chem. 46, 1393-1394

Maruyama S., Nagakami K., Tomizuka N. \& Suzuki H.K. (1985a) Angiotensin I converting inhibitor derived from an enzymatic hydrolysate of casein. II. Isolation and bradykinin-potentating activity on the uterus and the ileum of rats. Agric. Biol. Chem. 49, 1405-1409

Maruyama S., Suzuki H. \& Tomizuka N. (1985b) Effects of zinc ion on inhibition by angiotensin I converting enzyme inhibitor derived from casein. Agric. Biol. Chem. 49, 2809 2810

Maruyama S., Mitachi H., Tanaka H., Tomizuka N. \& Suzuki H. (1987) Studies on the active site and antihypertensive activity of angiotensin I converting enzyme inhibitors derived from casein. Agric. Biol. Chem. 51, 1581-1586

Maubois J.L. (1984) Separation, extraction and fractionation of milk protein components. Lait 64, 485-495

Maubois J.L. (1988) Whey, its biotechnological significance. VIII Symposium international des biotechnologies, Paris, 17-22 juillet

Maubois J.L., Roger L., Brulé G. \& Piot M. (1979) Hydrolysat enzymatique total des protéines de lactosérum. Obtentions et applications. Brevet Fr. $\mathrm{n}^{\circ} 7916483$

Maubois J.L., Pierre A., Fauquant J. \& Piot M. (1987) Industrial fractionation of main whey proteins. Bull. Int. Dairy Fed. 212, 154-159

Meisel H. (1986) Chemical characterization and opioid activity of an exorphin isolated from in vivo digests of casein. FEBS Lett. 196, 223-227 Meisel H. \& Frister H. (1988) Isolation and chemical characterization of a phosphopeptide from in vivo digests of casein. Communication. International Symposium «Milk proteins in human nutritionn, Kiel, RFA, 2-4 juin
Mellander O. (1950) The physiologic importance of the casein phosphopeptide calcium salts. II. Peroral calcium dosage of infants. Acta Soc. Med. Upsal. 55, 247-255

Mendy F. (1984) Fragmentation des protéines laitières. Interview recueillie par J. RajnchapelMessaï. Biofutur 24, 60-61

Migliore-Samour D. \& Jollès P. (1988) Casein, a prohormone with an immunomodulating role for the newborn? Experientia 44, 188-193

Morre M. (1988) Sanofi Recherche, Toulouse, France. Colloque INSERM/Industrie pharmaceutique, 18-19 avril

Mykkanen H.M. \& Wasserman R.H. (1980) Enhanced absorption of calcium by casein phosphopeptides in rachitic and normal chicks. J. Nutr. 110, 2141-2148

Naito H., Kawakami A. \& Imamura T. (1972) In vivo formation of phosphopeptides with calcium binding property in small intestinal tract of the rat fed on casein. Agric. Biol. Chem. 36, 409415

Naito H. \& Suzuki H. (1974) Further evidence for the formation in vivo of phosphopeptide in the intestinal lumen from dietary $\beta$-casein. Agric. Biol. Chem. 38, 1543-1545

Nedvidkova J., Kasafirek E., Dlabac A. \& Felt V. (1985) Effect of $\beta$-casomorphin and its analogues on serum prolactin in the rat. Exp. Clin. Endocrinol. 85, 249-252

Nieter M. \& Schatz H. (1981) Insolutropic action of endorphins and $\beta$-casomorphin, an opioid-like fragment of milk casein. Acta Endrocrinol. (Cph) 97, 243

Nieter M., Teschemacher H.J. \& Schatz H. (1981) Insulotropic action of endorphins and $\beta$-casomorphin, an opioid-like fragment of milk casein. Diabetologia 21, 309

Parker F., Migliore-Samour D., Floc'h.F., Zerial A., Werner G.H., Jollès J., Casaretto M., Zahn H. \& Jollès P. (1984) Immunostimulating hexapeptide from human casein : amino acid sequence, synthesis and biological properties. Eur. J. Biochem. 145, 677-682

Paroli E. (1988) Opioid peptides from food (the exorphins). WId Rev. Nutr. Diet. 55, 58-97

Pearce R.J. (1983) Thermal separation of betalactoglobulin and alpha-lactalbumin in bovine cheddar cheese whey. Aust. J. Dairy Technol. 38, 144-149

Pélissier J.P., Guilloteau P., Brulé G. \& Toullec R. (1983) Digestion des protéines du lait dans la caillette du veau préruminant. Evacuation 
gastrique après un repas d'épreuve. Reprod. Nutr. Dev. 23, 161-171

Peterson R.F., Nauman L.W. \& McMeekin T.L. (1958) The separation and amino acid composition of a pure phosphopeptide prepared from $\beta$ casein by the action of trypsin. J. Am. Chem. Soc. 80, 95-99

Petrilli P., Picone D., Caporale C., Addeo F., Auricchio S. \& Marino G. (1984) Does casomorphin have a functional role ? FEBS Lett. $169,53-56$

Pitt J., Barlow D., Hend W.C. \& Snatrilli T.V. (1974) Macrophages and the protective action of breast milk on necrotisis enterocolitis. Pediatr. Res. 8, 384

Raibaud P. \& Ducluzeau R. (1984) Les bactéries du tube digestif. Recherche 151, 12-21

Renner E. (1983) Milk and Dairy Products in Human Nutrition, Volkswirtschaftlicher Verlag, München

Richardson B.C. \& Mercier J.C. (1979) The primary structure of the ovine $\beta$-caseins. Eur. $J$. Biochem. 99, 285-297

Roger L. (1979) Contributions à la recherche d'une meilleure utilisation en alimentation humaine des composants glucidiques et protéiques du lactosérum grâce à l'emploi des techniques à membrane. Thèse de docteuringénieur, Rennes

Sato R., Noguchi T. \& Naito H. (1986) Casein phosphopeptide (CPP) enhances calcium absorption from the ligated segment of rat small intestine. J. Nutr. Sci. Vitaminol. 32, 67-76

Schusdziarra V., Specht J., Schick R., De la Fuente A., Holland A., Brantl V. \& Pfeiffer E.F. (1983a) Effect of $\beta$-casomorphins on somatostatin release in dogs. Endocrinology 112, 1948-1951

Schusdziarra V., Specht J., Schick R., De la Fuente A., Holland A. \& Pfeiffer E.F. (1983b) Effect of morphine, Leu-enkephalin and $\beta$ casomorphins on basal somatostatin release. Horm. Metab. Res. 15, 407-408

Segalen P. (1982) Caséines et caséinates, fabrication et utilisation. In : Protéines Animales. Technique et Documentation, Lavoisier, Paris, pp. 155-171

Shur B.D. (1984) Alpha-lactalbumin contraceptive. Brevet PTC/WO 84/04457

Spick G. (1988) Rôle de la lactotransferrine dans la nutrition martiale du nourrisson. Cah. Nutr. Diet. 23, 121-125
Stevens B.R., Fernandez A., Kneer C., Cerda J.J., Phillips M.I. \& Woodward E.R. (1988) Human intestinal brush border angiotensin converting enzyme activity and its inhibition by antihypertensive Ramipril. Gastroenterology 94 , 942-947

Sturner R.A. \& Chang K.J. (1988) Opioid peptide content in infant formulas. Pediatr. Res. 23, 4

Svedberg J., De Haas J., Leimenstoll G., Paul F. \& Teschemacher H. (1985) Demonstration of $\beta$-casomorphin immunoreactive materials in in vitro digests of bovine milk and in small intestine contents after bovine milk ingestion in adult humans. Peptides 6, 825-830

Terré E., Maubois J.L., Brulé G. \& Pierre A. (1986) Procédé d'obtention d'une matière première enrichie en caséine $\beta$, appareillage pour la mise en ceuvre de ce procédé et applications des produits obtenus. Brevet $\mathrm{Fr} . \mathrm{n}^{\circ} 8600325$

Teschemacher $\mathrm{H}$. (1987a) B-casomorphins : do they have physiological significance ? In : Human Lactation 3 (Goldman, ed.) Plenum Press, New York, pp. 213-225

Teschemacher H. (1987b) Casein derived opioid peptides : physiological significance ? Adv. Biosci. 65, 41-48

Tomé D., Dumontier A.M., Hautefeuille M. \& Desjeux J.F. (1987) Opiate activity and transepithelial passage of intact $\beta$-casomorphins in rabbit ileum. Am. J. Physiol. : Gastrointest. Liver Physiol. 253, G737-G744

Tomé D., Ben Mansour A., Hautefeuille M., Dumontier A.M. \& Desjeux J.F. (1988) Neuromediated action of $\beta$-casomorphins on ion transport in rabbit ileum. Reprod. Nutr. Dev. 28 , 909-918

Touraine F., Brulé G. \& Maubois J.L. (1987) Séparation chromatographique de peptides issus de l'hydrolyse enzymatique de protéines de lactosérum et de caséines. Lait 67, 419-436

Umbach M., Teschemacher $H_{\text {., Praetorius K., }}$ Hirschhauser R. \& Bostedt H. (1985) Demonstration of a $\beta$-casomorphin immunoreactive material in the plasma of newborn calves after milk intake. Regul. Peptides 12, 223-230

Wasserman R.H. (1964) Lactose stimulated intestinal absorption of calcium : a theory. Nature 201, 997-999

Wienbeck M., Bielfeld P., Karaus M. \& Erckenbrecht J.F. (1985) Is gut motility affected by exorphins? Dig. Dis. Sci. 30, 800 
Woods R.L., Searle F., Wilson P., Bagshawe K.D. \& Cooper E.H. (1977) Serum kappacasein in breast cancer. Eur. J. Cancer 13, 113117

Yvon M. \& Pélissier J.P. (1987) Characterization and kinetics of evacuation of peptides resulting from casein hydrolysis in the stomach of the calf. J. Agric. Food Chem. 35, 148-156
Zangerle P.F., Thirion A., Hendrick J.C. \& Franchimont P. (1978) Casein and other tumor markers in relation to cancer of the breast. Antibiot. Chemother. 22, 141-148

Zioudrou C., Streaty R.A. \& Klee W.A. (1979) Opioid peptides derived from food proteins : the exorphins. J. Biol. Chem. 254, 2446-2449

Zucker M. (1980) Plaquettes sanguines et coagulation. Pour Sci. 34, 37-47 